\title{
Body fat content, composition and distribution in Landrace and Iberian finishing pigs given ad libitum maize- and acorn-sorghum- maize-based diets
}

\author{
J. Morales ${ }^{1}$, M. D. Baucells ${ }^{1}$ †, J. F. Pérez ${ }^{1}$, J. Mourot $^{2}$ and J. Gasa ${ }^{1}$ \\ ${ }^{1}$ Departament de Ciència Animal i dels Aliments, Universitat Autònoma de Barcelona, 08193 Bellaterra, Spain \\ ${ }^{2}$ Institut National de la Recherche Agronomique, Station de Recherches Porcines, Saint-Gilles 35590, France \\ + Corresponding author. E-mail : mariadolores.baucells@uab.es
}

\begin{abstract}
We aimed to determine whether the dietary carbohydrate source altered body fat composition and distribution in finishing lean (Landrace) and obese (Iberian) swine. To this end, twenty-four finishing castrated male pigs (12 Iberian and 12 Landrace; $108 \mathrm{~kg}$ live weight) were offered two diets differing in the main carbohydrates source, maize (diet M) or acorn-sorghum-maize (diet A). Diets were formulated to have the same nutrient content, except for carbohydrate fractions: diet $M$ contained higher amount of starch (537 v. $389 \mathrm{~g} / \mathrm{kg}$ ) but less non-starch polysaccharides (118 v. $148 \mathrm{~g} / \mathrm{kg}$ ) than diet A. At an average weight of $133 \mathrm{~kg}$ live weight pigs were slaughtered and their carcasses were sampled to study lipogenesis, backfat and intramuscular fat composition. Iberian pigs showed a higher voluntary food intake than Landrace pigs (3.6 v. $2.4 \mathrm{~kg} / \mathrm{day} ; \mathrm{P}<0.001)$ but no significant differences in the daily weight gain. Diet $M$ tended to promote the highest food intake $(\mathrm{P}=0.09)$. Iberian pigs showed higher $(\mathrm{P}<0.01)$ lipogenic enzyme activities, backfat thickness $(71.7$ v. $31.9 \mathrm{~mm})$ and intramuscular fat content (40 to $95 \mathrm{~g} / \mathrm{kg}$ fresh muscle) than Landrace pigs, which was associated with their higher food intake. Furthermore, fat depots from Iberian pigs had higher $(\mathrm{P}<0.001)$ monounsaturated fatty acids (MUFA) and lower $(\mathrm{P}<0.05)$ polyunsaturated (PUFA) proportions than those from Landrace pigs. The backfat thickness of pigs given diet $M$ tended to be higher $(\mathrm{P}=0.07)$ than that of pigs given diet $A$, without differences in the intramuscular fat content. The higher backfat thickness found for diet $M$ was correlated with a lower PUFA proportion in diet than for diet $A(\mathrm{P}<0 \cdot 001)$. We conclude that body fat content, composition and lipogenic enzyme activities are markedly influenced by the animal breed and to a lesser extent by dietary characteristics.
\end{abstract}

Keywords: body fat, breed differences, carbohydrates, lipogenesis, pigs.

\section{Introduction}

The Iberian pig is an indigenous breed from the south-west Iberian Peninsula and the most important Mediterranean type, both in population size and in economic importance. It is characterized by early maturity, reduced lean deposition and high appetite, and is typically slaughtered at around $160 \mathrm{~kg}$ live weight. Most Iberian pig production is under extensive management on a Mediterranean forest territorial base : 'La Dehesa'. The food provided by 'La Dehesa' consists mostly of acorns, the fruit of genus Quercus, and grass, which contain high amounts of fermentable fibre, resistant starch and oleic acid (Lopez-Bote, 1998).

In recent years, the demand for Iberian pig products, which are considered high quality products, has increased. This is attributed to growing consumer acceptability, generally related to the high intramuscular fat content and oleic acid (Serra et al., 1998). In contrast, intensive swine production and selection based on lean growth rate have significantly decreased the intramuscular fat content of commercial breeds, to levels even under the minimal fat content (about $20 \mathrm{~g} / \mathrm{kg}$ ) ensuring 
acceptable meat quality (Karlsson et al., 1993; Mourot and Hermier, 2001). Although most of these differences are due to genetic causes (Ovilo et al., 2000), the diet may also be involved (Pond et al., 1988).

The dietary factors influencing fat accretion and lipogenesis are well known. In particular, energy and carbohydrate intake have a predominant rôle in fatty acid synthesis de novo (Hudgins et al., 2000), while high-lipid diets inhibit endogenous lipogenesis (Allee et al., 1971). For most lipogenic enzymes, an increase in glucose metabolism is required to induce transcription (Towle et al., 1997). However, in vitro studies have shown that other precursors like acetate, lactate, citrate and glycerol can promote lipogenesis in pigs (Mersmann, 1986). In particular, we would like to highlight the high utilization by some tissues, such as muscles, of free fatty acids like acetate, which probably provide precursors for muscular oxidation and lipogenesis (Mittendorfer et al., 1998). From this perspective, dietary carbohydrates, either through the diet or fermentation, may promote diverse responses in lipogenic activities. However, little is known about the effect of specific dietary ingredients, especially carbohydrates, on the lipogenesis in adipose and muscular tissues, and the intramuscular fat content. In this regard, Ramsey et al. (1990) described differences in fat accretion, in particular in the intramuscular fat depot, in growing pigs given various cereal grain sources (maize, whey or sorghum).

This experiment was undertaken to evaluate in intensive conditions the effects of genotype and feeding differing in carbohydrate sources (maize- $v$. acorn-sorghum-maize-based diets) on:(1) fat accretion and fatty acid profile in various fat depots (subcutaneous, intermuscular and intramuscular fats) and (2) lipogenic enzyme activities in these tissues.

A preliminary account of part of the present study has been published elsewhere (Morales et al., 2002a and $b$ ).

\section{Material and methods}

The experiment was approved by the Animal Protocol Review Committee of the Universitat Autònoma de Barcelona. The treatment, housing,

Table 1 Composition $(\mathrm{g} / \mathrm{kg})$ and nutrient content $(\mathrm{g} / \mathrm{kg}$ dry matter) of the experimental diets

\begin{tabular}{|c|c|c|c|c|}
\hline & \multicolumn{2}{|c|}{ Pre-experimental diets } & \multicolumn{2}{|c|}{ Experimental diets } \\
\hline & Diet M & Diet A & Diet M & Diet A \\
\hline \multicolumn{5}{|l|}{ Ingredients (g/kg) } \\
\hline Maize & $753 \cdot 6$ & $376 \cdot 4$ & $741 \cdot 7$ & $206 \cdot 8$ \\
\hline Sorghum & & $275 \cdot 0$ & & $200 \cdot 0$ \\
\hline Semi-decorticated acorn & & $125 \cdot 0$ & & $400 \cdot 0$ \\
\hline Acorn shell & $15 \cdot 0$ & & $48 \cdot 0$ & \\
\hline Soya-bean meal & $197 \cdot 4$ & $194 \cdot 7$ & $151 \cdot 7$ & $159 \cdot 0$ \\
\hline Maize oil & & $7 \cdot 0$ & & $14 \cdot 0$ \\
\hline Olive oil & $12 \cdot 0$ & & $38 \cdot 0$ & \\
\hline $\mathrm{CaCO}_{3}$ & $7 \cdot 4$ & $6 \cdot 8$ & $7 \cdot 0$ & $4 \cdot 4$ \\
\hline Dicalcium phosphate & $6 \cdot 8$ & $7 \cdot 3$ & $5 \cdot 8$ & 7.9 \\
\hline Salt & $2 \cdot 3$ & $2 \cdot 3$ & $2 \cdot 3$ & $2 \cdot 4$ \\
\hline Vitamin/mineral mixt & $4 \cdot 0$ & $4 \cdot 0$ & $4 \cdot 0$ & $4 \cdot 0$ \\
\hline Chromium III oxide & $1 \cdot 5$ & 1.5 & 1.5 & 1.5 \\
\hline \multicolumn{5}{|l|}{ Nutrient analysis (g/kg DM) } \\
\hline Crude protein & $161 \cdot 9$ & 171.9 & $136 \cdot 6$ & $144 \cdot 6$ \\
\hline Hemicellulose & $85 \cdot 6$ & $97 \cdot 0$ & $111 \cdot 3$ & $91 \cdot 8$ \\
\hline Cellulose & $42 \cdot 4$ & $52 \cdot 6$ & $47 \cdot 5$ & $63 \cdot 4$ \\
\hline Lignin & $14 \cdot 4$ & $18 \cdot 2$ & $19 \cdot 8$ & $25 \cdot 6$ \\
\hline Total starch & $561 \cdot 0$ & $513 \cdot 4$ & 536.5 & $389 \cdot 1$ \\
\hline Resistant starch & $107 \cdot 0$ & $106 \cdot 0$ & $143 \cdot 0$ & $102 \cdot 0$ \\
\hline Non-starch polysaccharides & $119 \cdot 4$ & $114 \cdot 3$ & $118 \cdot 3$ & $148 \cdot 0$ \\
\hline Crude fat & $52 \cdot 4$ & $53 \cdot 3$ & $82 \cdot 6$ & $76 \cdot 6$ \\
\hline Gross energy (kcal/kg) & 3973 & 3938 & 4036 & 4093 \\
\hline
\end{tabular}

+ Vitamin/mineral mix provided the following $(\mathrm{mg} / \mathrm{kg}$ diet): retinol 2.1; cholecalciferol 0.045; alpha-tocopherol 10; phytylmenaquinone 1 ; thiamine 1 ; riboflavin 4 ; pyridoxine 2; cyanocobalamin 0.02 ; biotin 0.01 ; niacin 18 ; Ca-d-pantothenic acid 10; choline 175; Fe 80; Zn 110; Cu 90; Mn 50; Co 0.1; I 1; Se 0.2. 
husbandry and slaughtering conditions conformed to the European Union guidelines.

\section{Experimental design}

Twenty-four finishing castrated male pigs (12 Landrace, 12 Iberian; $88 \pm 6.4 \mathrm{~kg}$ live weight (LW)) were housed in 12 pens (two animals each) in an environmentally controlled building. Animals from each breed were randomly divided in two groups and given maize- or acorn-sorghum-maize-based diets (diets $\mathrm{M}$ and $\mathrm{A}$, respectively) in two phases: pre-experimental phase, from 88 to $108 \mathrm{~kg}$ LW, for animal adaptation to diets, and experimental phase during 28 days, from 108 to $133 \mathrm{~kg}$ LW, after which they were slaughtered. Landrace and Iberian pigs reached the initial experimental weight at about 180 and 225 days of age, respectively.

The ingredient and nutrient contents of the diets are presented in Table 1. Within phases, diets were formulated to be isoenergetic and isonitrogenous, following National Research Council (1998) recommendations.

Experimental diet M contained mostly maize (742 g/ $\mathrm{kg}$ ) and experimental diet A contained decorticated acorn $(400 \mathrm{~g} / \mathrm{kg})$, the fruit of genus Quercus, sorghum $(200 \mathrm{~g} / \mathrm{kg})$ and maize $(207 \mathrm{~g} / \mathrm{kg})$. The carbohydrate fraction differed between diets, and diet $\mathrm{M}$ contained a higher total starch content than diet A (537 v. $389 \mathrm{~g} / \mathrm{kg}$ dry matter (DM)), and a lower non-starch polysaccharide (NSP) content (118 v. $148 \mathrm{~g} / \mathrm{kg} \mathrm{DM})$. The shell proportion of ground acorns was reduced by rough grinding (down to $130 \mathrm{~g} / \mathrm{kg}$ ). To equalize the composition of the noncarbohydrate fraction between diets, in particular the content in oleic acid and shells from acorn and

Table 2 Fatty acid profiles (\%; saturated (SFA), monounsaturated (MUFA) and polyunsaturated fatty acids (PUFA)) of the experimental diets

\begin{tabular}{|c|c|c|c|c|}
\hline & \multicolumn{2}{|c|}{ Pre-experimental diets } & \multicolumn{2}{|c|}{ Experimental diets } \\
\hline & Diet M & Diet A & Diet M & Diet A \\
\hline SFA & $16 \cdot 48$ & $16 \cdot 27$ & $16 \cdot 26$ & $17 \cdot 26$ \\
\hline 16: 0 & $12 \cdot 77$ & $13 \cdot 11$ & $12 \cdot 48$ & $13 \cdot 76$ \\
\hline 18: 0 & 3.09 & $2 \cdot 63$ & $3 \cdot 14$ & 2.98 \\
\hline MUFA & $39 \cdot 04$ & $36 \cdot 10$ & $52 \cdot 79$ & $46 \cdot 06$ \\
\hline 18: $1(n-9)$ & $36 \cdot 88$ & 34.55 & $50 \cdot 38$ & $44 \cdot 54$ \\
\hline PUFA & $44 \cdot 48$ & $47 \cdot 63$ & $30 \cdot 95$ & $36 \cdot 68$ \\
\hline n-6 & $42 \cdot 23$ & $45 \cdot 35$ & $29 \cdot 40$ & 34.75 \\
\hline 18: 2(n-6) & $41 \cdot 88$ & $45 \cdot 03$ & $29 \cdot 16$ & $34 \cdot 51$ \\
\hline$n-3$ & $2 \cdot 05$ & $2 \cdot 10$ & $1 \cdot 35$ & 1.75 \\
\hline 18: 3(n-3) & $2 \cdot 01$ & $2 \cdot 09$ & $1 \cdot 34$ & $1 \cdot 57$ \\
\hline UFA/SFA† & $5 \cdot 07$ & $5 \cdot 14$ & $5 \cdot 15$ & $4 \cdot 79$ \\
\hline
\end{tabular}

+ Unsaturated fatty acid : SFA ratio. linoleic acid from maize, olive oil and isolated shells were added to diet $M$ and maize oil was added to $\operatorname{diet} \mathrm{A}$. The fatty acid profile of diets is presented in Table 2.

Food intake by pen (three per breed 5 dietary treatment) and individual live weight were recorded weekly and the average daily weight gain (six per breed 5 dietary treatment) and food conversion ratios (three per breed 5 dietary treatment) were calculated.

\section{Biopsy procedures}

Three subcutaneous fat samples from each pig were taken through biopsy before (pre-adaptation, $88 \pm$ $6.4 \mathrm{~kg} \mathrm{LW})$ and at the end of the pre-experimental period $(108 \pm 4.6 \mathrm{~kg} \mathrm{LW})$, and in the slaughter facilities (post experimental, $133 \pm 5 \cdot 1 \mathrm{~kg}$ LW). Samples were obtained from the lumbar area at about $5 \mathrm{~cm}$ from the spinous process of the fourth lumbar vertebra, using a Czech gun with an adapted cannula (PPB-2 Biotech, Nitra, Slovakia). All samples were stored at $-20^{\circ} \mathrm{C}$ until fatty acid (FA) profile analysis. All necessary measures were taken to prevent animal discomfort during and after all processes.

\section{Sampling and carcass data}

The experiment was designed to slaughter animals at $130 \mathrm{~kg}$, which is between commercial weight in Landrace $(100 \mathrm{~kg})$ and Iberian $(160 \mathrm{~kg})$ pigs. Pigs were slaughtered in a commercial slaughterhouse, without previous fasting and after $\mathrm{CO}_{2}$ stunning. Backfat was measured in the mid line near the 15 th to 16th costal area. Samples from adipose tissue (subcutaneous backfat and intermuscular fat from the neck region, ventro-medial to the semispinatus muscle) and two muscles samples from the semimembranosus and the gluteus medius were taken within less than $30 \mathrm{~min}$ after slaughter, immediately frozen in liquid $\mathrm{N}_{2}$ and stored at $-80^{\circ} \mathrm{C}$ until the analysis of lipogenic enzyme activity. For the lipid analyses, samples from three muscles, longissimus dorsi, gluteus medius and masseter, were taken and freeze-dried before analysis for lipid content and FA profile determinations.

\section{Analytical procedures}

Chemical analyses of the diets were conducted in accordance with the Association of Official Analytical Chemists (AOAC, 1995) for DM, ash, crude protein $(\mathrm{CP})$ and crude fat $(\mathrm{CF})$ and tannins (quercitannic acid). The fat content of the muscle samples was also extracted following the Soxhlet procedure. The carbohydrate fraction of diets was analysed following Theander (1991) and resistant starch following Champ (1992). Both methods have been widely explained elsewhere (Morales et al., 2002b). 
Table 3 Effect of breed and carbohydrate source in diet on growth and slaughter characteristics

\begin{tabular}{|c|c|c|c|c|c|c|c|}
\hline & \multicolumn{4}{|c|}{ Breed } & \multirow[b]{3}{*}{ s.e. } & & \\
\hline & \multicolumn{2}{|c|}{ Landrace } & \multicolumn{2}{|c|}{ Iberian } & & \multicolumn{2}{|c|}{ Significancet } \\
\hline & Diet $\mathrm{M}$ & Diet A & Diet $M$ & Diet A & & Breed & Diet \\
\hline Initial live weight (LW; kg) & $106 \cdot 7$ & $106 \cdot 7$ & $111 \cdot 2$ & $108 \cdot 8$ & 1.89 & $\ddagger$ & \\
\hline Final LW (kg) & $134 \cdot 2$ & $128 \cdot 5$ & $137 \cdot 8$ & $130 \cdot 3$ & $1 \cdot 47$ & $\ddagger$ & $* * *$ \\
\hline Daily food intake (g) & 2574 & 2301 & 3739 & 3405 & 128 & $\stackrel{+}{+}$ & $\ddagger$ \\
\hline Daily LW gain $(\mathrm{g})$ & 740 & 612 & 936 & 613 & $72 \cdot 0$ & & * \\
\hline Food : gain ratio & 3.48 & $3 \cdot 81$ & $4 \cdot 00$ & $5 \cdot 75$ & 0.565 & $\ddagger$ & \\
\hline Hot carcass weight $(\mathrm{kg})$ & $104 \cdot 8$ & $99 \cdot 6$ & $108 \cdot 4$ & $100 \cdot 3$ & $1 \cdot 35$ & & $* * *$ \\
\hline Killing-out proportion (g/kg) & 781 & 775 & 787 & 770 & $6 \cdot 20$ & & $\ddagger$ \\
\hline
\end{tabular}

+ Interaction breed $X$ diet was not significant $(P>0.05)$.

$\ddagger$ Approached significance $(P<0 \cdot 10)$.

The lipogenic enzyme activities of subcutaneous, inter- and intramuscular adipose tissues were determined as follows: weighed quantities of adipose tissue or muscle samples were homogenized in $0.25 \mathrm{~mol} / 1$ sucrose buffer and centrifuged at $30000 \mathrm{~g}$ for $40 \mathrm{~min}$. Supernatants were analysed for malic enzyme (ME, EC 1.1.1.40) and glucose-6phosphate dehydrogenase (G6PDH, EC 1.1.1.49) using a modification (Gandemer et al., 1983) of the methods of Fitch et al. (1959), and Hsu and Lardy (1969), respectively. NADPH formation was measured at $37^{\circ} \mathrm{C}$ by absorbance at $340 \mathrm{~nm}$. Soluble proteins in adipose tissue supernatants were determined using the bicinchoninic acid protein assay (BCA Protein Assay Kit, PIERCE, Rockford, IL). ME and G6PDH activities were expressed as $\mu \mathrm{mol}$ of NADPH produced per min per $\mathrm{g}$ muscular tissue or perg supernatant protein from adipose tissue.

Fatty acid profiles in experimental diets (Table 2) and in the samples from the carcass were determined by lipid extraction (Folch et al., 1957) and methylation with $20 \%$ boron trifluoride-methanol complex in methanolic solution (Guardiola et al., 1994). The fatty acid methyl esters were separated on a GC-14A Shimadzu gas chromatograph equipped with a flame ionization detector and a capillary column (30 m $50.53 \mathrm{~mm}$ i. d. ) with a film thickness $(0.5 \mu \mathrm{m})$ of stationary phase of $30 \%$ methyl- $+70 \%$ cyanopropyl-polysiloxane (BPX70). Helium was used as the carrier gas. Oven temperature was programmed as follows : from $75^{\circ} \mathrm{C}$ to $148^{\circ} \mathrm{C}$ at $4^{\circ} \mathrm{C} /$ min; from $148^{\circ} \mathrm{C}$ to $158^{\circ} \mathrm{C}$ at $2.5^{\circ} \mathrm{C} / \mathrm{min}$ and from $158^{\circ} \mathrm{C}$ to $240^{\circ} \mathrm{C}$ at $5^{\circ} \mathrm{C} / \mathrm{min}$. The other chromatographic conditions were as follows : injector and detector temperature, $280^{\circ} \mathrm{C}$; head pressure, 8.7 p. s. i. and sample volume injected, $0 \cdot 3 \mu$ for the food and adipose tissue samples; and $0.5 \mu \mathrm{l}$ for the muscle samples. Fatty acids were identified by comparison with the retention time of the corresponding pure standards. Quantification was carried out through area normalization and results were expressed as each FA percentage of total fatty acids.

Table 4 Effect of breed and carbohydrate source in diet on backfat thickness $(\mathrm{mm})$ and intramuscular fat content $(\mathrm{g} / 100 \mathrm{~g}$ fresh muscle) of longissimus dorsi, gluteus medius and masseter

\begin{tabular}{|c|c|c|c|c|c|c|c|}
\hline & \multicolumn{4}{|c|}{ Breed } & \multirow[b]{3}{*}{ s.e. } & & \\
\hline & \multicolumn{2}{|c|}{ Landrace } & \multicolumn{2}{|c|}{ Iberian } & & \multicolumn{2}{|c|}{ Significancet } \\
\hline & Diet M & Diet A & Diet M & Diet A & & Breed & Diet \\
\hline Backfat thickness & $35 \cdot 4$ & $28 \cdot 3$ & $72 \cdot 5$ & $70 \cdot 8$ & $2 \cdot 44$ & $* * *$ & $\ddagger$ \\
\hline Longissimus dorsi & $2 \cdot 42$ & $2 \cdot 23$ & $6 \cdot 26$ & $5 \cdot 80$ & $0 \cdot 602$ & $* * *$ & \\
\hline Gluteus medius & 2.98 & 3.07 & $9 \cdot 43$ & $8 \cdot 21$ & 0.740 & $* * *$ & \\
\hline Masseter & $2 \cdot 32$ & $2 \cdot 34$ & $4 \cdot 07$ & $4 \cdot 31$ & 0.404 & $* * *$ & \\
\hline
\end{tabular}

+ Interaction breed $X$ diet was not significant $(P>0.05)$.

$\ddagger$ Approached significance $(P<0 \cdot 10)$. 
Table 5 Effect of breed and carbohydrate source in diet on the activity of malic enzyme (ME) and glucose-6-phosphate dehydrogenase $(G 6 P D H)$ determined in the adipose tissue (subcutaneous backfat and intermuscular; $\mu m o l$ NADPH per min per $g$ protein) and muscle (gluteus medius and semimembranosus; $\mu$ mol NADPH per min per $g$ )

\begin{tabular}{|c|c|c|c|c|c|c|c|c|}
\hline & \multicolumn{4}{|c|}{ Breed } & \multirow[b]{3}{*}{ s.e. } & & & \\
\hline & \multicolumn{2}{|c|}{ Landrace } & \multicolumn{2}{|c|}{ Iberian } & & \multicolumn{3}{|c|}{ Significance } \\
\hline & Diet M & Diet A & Diet M & Diet A & & Breed & Diet & Interaction \\
\hline \multicolumn{9}{|l|}{ Malic enzyme } \\
\hline \multicolumn{9}{|l|}{ Adipose tissue } \\
\hline Backfat & $4 \cdot 23$ & $3 \cdot 26$ & $7 \cdot 60$ & $6 \cdot 24$ & 0.594 & $* * *$ & \multirow[t]{2}{*}{$\ddagger$} & \\
\hline Intermuscular & 1.23 & $1 \cdot 16$ & 0.84 & 0.49 & $0 \cdot 150$ & $* *$ & & \\
\hline \multicolumn{9}{|l|}{ Muscle } \\
\hline G. medius & 3.38 & $3 \cdot 10$ & $6 \cdot 42$ & $6 \cdot 44$ & 0.647 & $* * *$ & & \\
\hline Semimembranosus & $2 \cdot 89$ & 3.73 & $6 \cdot 69$ & $5 \cdot 48$ & $0 \cdot 424$ & $* * *$ & & * \\
\hline \multicolumn{9}{|l|}{ G6PDH } \\
\hline \multicolumn{9}{|l|}{ Adipose tissue } \\
\hline Backfat & 2.59 & $2 \cdot 28$ & $3 \cdot 31$ & 3.06 & $2 \cdot 244$ & $* *$ & & \\
\hline Intermuscular & 0.89 & 0.93 & 0.56 & 0.40 & 0.081 & $* * *$ & & \\
\hline \multicolumn{9}{|l|}{ Muscle } \\
\hline G. medius & $0 \cdot 07$ & $-0 \cdot 01$ & 0.87 & $0 \cdot 80$ & $0 \cdot 241$ & $* *$ & & \\
\hline Semimembranosus & -0.03 & 0.03 & 0.31 & $0 \cdot 24$ & 0.059 & $* * *$ & & \\
\hline
\end{tabular}

$\ddagger$ Approached significance $(P<0 \cdot 10)$.

\section{Statistical analysis}

Data were analysed using the GLM (generalized linear model) procedure of the SAS package (SAS Institute Inc., SAS Campus Drive, Cary, NC 27513) for a factorial arrangement of treatments. The fitted model included the breed, diet and their interaction as fixed effects. Carcass weight was initially included in the model as a covariate, except for performance parameters. However, it was not significant and so the means presented are those obtained by omitting this factor in the model. The differences between means were determined using the Tukey's test. In all cases, $P<0.05$ was considered significant.

\section{Results}

The performance of the animals during the preexperimental period has been reported elsewhere (Morales et al., 2002a). Briefly, Iberian pigs showed higher food intake than Landrace pigs, with no differences between diets. However, no differences were observed between treatments for the average daily gain (ADG) in that previous period. The performance and slaughter parameters of the animals during the experimental period are summarized in Table 3. Iberian pigs again showed higher daily food intake than Landrace pigs (3.6 v. $2.4 \mathrm{~kg} /$ day; $P<0.001$ ), with no difference between breeds for ADG, leading to food:gain ratios observed in Iberian (4.9), that tended to be higher than in Landrace (3.6) $(P=0.09)$. Between diets, diet
M promoted a higher daily food intake $(P=0.07)$ and ADG $(P<0.05)$ than diet $A$. The differences in performance parameters between experimental treatments were larger than expected and so we did not slaughter the animals at the same weight. The average slaughter weight differed between breeds (134.1 v. $131.4 \mathrm{~kg} \mathrm{LW} ; P=0.08)$ and diets $(136.0$ v. $129.4 \mathrm{~kg} \mathrm{LW} ; P<0.001)$, being higher for Iberian and $\operatorname{diet} \mathrm{M}$ than for Landrace and $\operatorname{diet} \mathrm{A}$, respectively.

The intramuscular fat content (longissimus dorsi, gluteus medius and masseter muscles) and backfat thickness are presented in Table 4 . The gluteus medius showed the highest lipid content in both diets. The longissimus dorsi had a higher lipid content than masseter in Iberian pigs, but both showed a similar content in Landrace pigs. The intramuscular lipid content was greater in Iberian than in Landrace pigs $(P<0.001)$ and no differences were observed between diets. Backfat thickness was higher in Iberian than in Landrace pigs (71.7 v. $31.9 \mathrm{~mm}$; $P<0.001)$ and tended to be higher for diet $\mathrm{M}$ than for $\operatorname{diet} \mathrm{A}(P=0 \cdot 07)$.

Lipogenic enzyme activities (ME and G6PDH) in adipose (subcutaneous and intermuscular; $\mu \mathrm{mol}$ NADPH per min per g protein) and muscle (gluteus medius and semimembranosus; $\mu$ mol NADPH per min per $g$ tissue) tissues are shown in Table 5. G6PDH activity was much lower than ME activity in both breeds, especially in the intramuscular adipose 
Table 6 Effect of breed and carbohydrate source in diet on fatty acid composition (\%) of backfat samples taken at different stagest

\begin{tabular}{|c|c|c|c|c|c|c|c|c|}
\hline & \multicolumn{2}{|c|}{ Landrace } & \multicolumn{2}{|c|}{ Iberian } & \multirow[b]{2}{*}{ s.e. } & \multirow{2}{*}{\multicolumn{3}{|c|}{$\frac{\text { Significance }}{\text { Breed }}$}} \\
\hline & Diet M & Diet A & Diet M & Diet A & & & & \\
\hline \multicolumn{9}{|c|}{ Pre-adaptation } \\
\hline SFA & $40 \cdot 3$ & $39 \cdot 6$ & $37 \cdot 1$ & $36 \cdot 4$ & 0.79 & \multicolumn{3}{|c|}{$* * *$} \\
\hline 16: 0 & $26 \cdot 3$ & $26 \cdot 3$ & $23 \cdot 8$ & $23 \cdot 5$ & $0 \cdot 67$ & \multicolumn{3}{|c|}{$* * *$} \\
\hline 18: 0 & $12 \cdot 3$ & 11.5 & $11 \cdot 4$ & $11 \cdot 0$ & 0.53 & \\
\hline MUFA & $48 \cdot 7$ & $49 \cdot 0$ & $52 \cdot 1$ & $52 \cdot 5$ & 0.65 & \multicolumn{3}{|c|}{$* * *$} \\
\hline 18: 1(n-9) & $43 \cdot 1$ & $42 \cdot 9$ & $45 \cdot 3$ & $45 \cdot 3$ & 0.65 & \multicolumn{3}{|c|}{$* *$} \\
\hline PUFA & $11 \cdot 0$ & $11 \cdot 5$ & $10 \cdot 7$ & $11 \cdot 0$ & $0 \cdot 41$ & \\
\hline$n-6$ & $10 \cdot 0$ & $10 \cdot 4$ & $9 \cdot 8$ & $10 \cdot 1$ & 0.32 & \\
\hline 18: 2(n-6) & $9 \cdot 3$ & $9 \cdot 7$ & $9 \cdot 0$ & $9 \cdot 3$ & $0 \cdot 30$ & \\
\hline$n-3$ & 0.87 & 0.94 & 0.71 & 0.88 & $0 \cdot 105$ & \multirow{2}{*}{\multicolumn{3}{|c|}{ * }} \\
\hline \multirow[t]{3}{*}{ 18: 3(n-3) } & $0 \cdot 70$ & 0.75 & 0.54 & 0.64 & $0 \cdot 053$ & & & \\
\hline & & & & & & \multicolumn{3}{|c|}{ Significance } \\
\hline & & & & & & Breed & Diet & Interaction \\
\hline \multicolumn{9}{|c|}{ Pre-experimental } \\
\hline SFA & $40 \cdot 5$ & $41 \cdot 1$ & $36 \cdot 9$ & $37 \cdot 1$ & 0.90 & $* * *$ & & \\
\hline 16: 0 & $26 \cdot 4$ & $28 \cdot 1$ & $23 \cdot 6$ & $24 \cdot 7$ & 0.87 & $* *$ & & \\
\hline 18: 0 & $12 \cdot 4$ & $11 \cdot 1$ & $11 \cdot 3$ & $10 \cdot 3$ & $0 \cdot 44$ & $*$ & * & \\
\hline MUFA & $48 \cdot 8$ & $48 \cdot 0$ & $52 \cdot 2$ & $51 \cdot 9$ & 0.74 & $* * *$ & & \\
\hline 18: 1(n-9) & $43 \cdot 5$ & $42 \cdot 2$ & $45 \cdot 1$ & $44 \cdot 6$ & 0.68 & $* *$ & & \\
\hline PUFA & $10 \cdot 6$ & $11 \cdot 0$ & $10 \cdot 9$ & $11 \cdot 0$ & 0.29 & & & \\
\hline$n-6$ & 9.8 & $10 \cdot 3$ & $10 \cdot 1$ & $10 \cdot 4$ & $0 \cdot 25$ & & & \\
\hline 18: 2(n-6) & $9 \cdot 3$ & 9.8 & $9 \cdot 4$ & 9.7 & $0 \cdot 21$ & & $\ddagger$ & \\
\hline$n-3$ & 0.68 & 0.65 & 0.76 & 0.68 & $0 \cdot 047$ & & & \\
\hline 18: 3(n-3) & $0 \cdot 60$ & $0 \cdot 61$ & $0 \cdot 61$ & 0.58 & 0.023 & & & \\
\hline \multicolumn{9}{|c|}{ Post experimental } \\
\hline SFA & $37 \cdot 6$ & $37 \cdot 3$ & $37 \cdot 6$ & $34 \cdot 6$ & 0.66 & $\ddagger$ & * & * \\
\hline 16: 0 & $23 \cdot 7$ & $23 \cdot 9$ & $24 \cdot 2$ & $22 \cdot 5$ & $0 \cdot 39$ & & $\ddagger$ & * \\
\hline 18: 0 & $12 \cdot 1$ & $11 \cdot 6$ & $11 \cdot 4$ & $10 \cdot 2$ & 0.44 & $*$ & $\ddagger$ & \\
\hline MUFA & $50 \cdot 8$ & $49 \cdot 6$ & $51 \cdot 6$ & $53 \cdot 0$ & $0 \cdot 51$ & $* * *$ & & $*$ \\
\hline 18: 1(n-9) & $45 \cdot 3$ & $44 \cdot 3$ & $46 \cdot 2$ & $47 \cdot 1$ & $0 \cdot 54$ & $* *$ & & $\ddagger$ \\
\hline PUFA & 11.7 & $13 \cdot 1$ & $10 \cdot 8$ & $12 \cdot 3$ & 0.33 & $*$ & $* * *$ & \\
\hline$n-6$ & $10 \cdot 6$ & $12 \cdot 0$ & $10 \cdot 0$ & $11 \cdot 4$ & $0 \cdot 30$ & $\ddagger$ & $* * *$ & \\
\hline 18: 2(n-6) & $9 \cdot 7$ & $11 \cdot 0$ & $9 \cdot 2$ & $10 \cdot 4$ & $0 \cdot 29$ & $\ddagger$ & $* * *$ & \\
\hline$n-3$ & 0.79 & 0.89 & 0.66 & 0.79 & 0.022 & $* * *$ & $* * *$ & \\
\hline 18: 3(n-3) & 0.59 & $0 \cdot 66$ & $0 \cdot 48$ & 0.55 & $0 \cdot 018$ & $* * *$ & $* * *$ & \\
\hline
\end{tabular}

+ SFA = total saturated fatty acids; MUFA = total monounsaturated fatty acids; PUFA = total polyunsaturated fatty acids; n-3 = total n-3 polyunsaturated fatty acids; $n-6=$ total n- 6 polyunsaturated fatty acids.

$\ddagger$ Approached significance $(P<0 \cdot 10)$.

tissues. Lipogenic enzyme activities were higher in Iberian than in Landrace pigs, both in adipose and muscle tissues $(P<0 \cdot 01)$, except for the enzymatic activity of intermuscular fat tissue, which was higher in Landrace than in Iberian pigs $(P<0.01)$. No differences were observed between diets $(P>0.05)$, except for the ME activity in subcutaneous tissue, which tended to be higher in diet $\mathrm{M}$ than in diet $\mathrm{A}$ (5.9 v. $4.8 \mu \mathrm{mol}$ NADPH per min perg protein; $P=0.06)$.

Table 6 presents the FA profile of three samples obtained from backfat during the pre-experimental and the experimental periods. Differences between breeds had been detected before the preexperimental period, when animals had been given the same diet. The backfat from Iberian pigs showed a lower $(P<0.001)$ proportion of saturated fatty acids (SFA) and linolenic acid $(P<0.05)$ and a higher proportion $(P<0.001)$ of monounsaturated fatty acids (MUFA) than that from Landrace pigs. At the end of the experiment, the backfat from lberian pigs and pigs given diet $\mathrm{M}$ had a lower proportion of polyunsaturated fatty acids (PUFA), evident both in $\mathrm{n}-6$ and in $\mathrm{n}-3 \mathrm{FA}$, than that from Landrace pigs $(P<0.05)$ and pigs given diet A $(P<0.001)$, 
respectively. However, SFA and MUFA proportions differed between breeds depending on the experimental diet offered : Iberian pigs given diet $\mathrm{A}$ showed the lowest SFA (breed 5 diet $P<0.05$ ) and the highest MUFA (breed 5 diet $P<0.05$ ) proportions, promoting significant differences between experimental treatments. Regardless of the interaction effect, the MUFA proportion in Iberian was significantly higher $(P<0.001)$ than in Landrace pigs $(52 \cdot 3$ v. $50 \cdot 2 \%)$.
Table 7 shows the results obtained for the FA composition of intramuscular fat in longissimus dorsi, gluteus medius and masseter. The proportion of SFA, especially that of palmitic acid, was very similar in all three muscle locations and all treatments (between 33 and 39\% SFA). MUFA, in particular oleic acid, were the most abundant of the FA in all three muscle locations ( $>47 \%$ ), especially for Iberian pigs, which showed significantly higher MUFA $(P<0.001)$ and oleic acid proportions than Landrace pigs. As described above for the backfat depot, the intramuscular fat FA profile also tended to show a

Table 7 Effect of breed and carbohydrate source in diet on fatty acid composition (\%) of intramuscular fat (longissimus dorsi, gluteus medius and masseter) $\dagger$

\begin{tabular}{|c|c|c|c|c|c|c|c|c|}
\hline & \multicolumn{4}{|c|}{ Breed } & \multirow[b]{3}{*}{ s.e. } & & & \\
\hline & \multicolumn{2}{|c|}{ Landrace } & \multicolumn{2}{|c|}{ Iberian } & & \multicolumn{3}{|c|}{ Significance } \\
\hline & Diet M & Diet A & Diet M & Diet A & & Breed & Diet & Interaction \\
\hline \multicolumn{9}{|c|}{ Longissimus dorsi } \\
\hline SFA & $37 \cdot 1$ & $37 \cdot 7$ & $36 \cdot 1$ & $35 \cdot 2$ & 1.53 & & & \\
\hline 16: 0 & $23 \cdot 5$ & $23 \cdot 8$ & $24 \cdot 5$ & $23 \cdot 8$ & 1.06 & & & \\
\hline 18: 0 & $11 \cdot 3$ & $10 \cdot 8$ & 9.3 & 9.0 & $0 \cdot 60$ & $* *$ & & \\
\hline MUFA & $51 \cdot 1$ & $47 \cdot 5$ & $56 \cdot 6$ & $57 \cdot 3$ & $1 \cdot 33$ & $* * *$ & & $\ddagger$ \\
\hline 18: 1(n-9) & $43 \cdot 1$ & 39.8 & $47 \cdot 1$ & $46 \cdot 2$ & 1.09 & $* * *$ & * & \\
\hline PUFA & $11 \cdot 6$ & $14 \cdot 6$ & $7 \cdot 1$ & $7 \cdot 5$ & 1.05 & $* * *$ & & \\
\hline $\mathrm{n}-6$ & $10 \cdot 7$ & $13 \cdot 5$ & $6 \cdot 6$ & $6 \cdot 9$ & $1 \cdot 15$ & $* * *$ & & \\
\hline 18: 2(n-6) & 8.4 & $10 \cdot 6$ & $5 \cdot 4$ & $5 \cdot 6$ & $0 \cdot 83$ & $* * *$ & & \\
\hline$n-3$ & 0.85 & $1 \cdot 00$ & $0 \cdot 38$ & 0.38 & $0 \cdot 201$ & $* *$ & & \\
\hline 18: 3(n-3) & 0.63 & 0.74 & $0 \cdot 26$ & $0 \cdot 25$ & $0 \cdot 184$ & * & & \\
\hline \multicolumn{9}{|c|}{ Gluteus medius } \\
\hline SFA & $36 \cdot 6$ & $37 \cdot 1$ & 38.6 & $35 \cdot 0$ & 0.94 & & & * \\
\hline 16: 0 & $23 \cdot 7$ & $24 \cdot 2$ & $26 \cdot 2$ & 23.9 & 0.63 & $\ddagger$ & & * \\
\hline 18: 0 & $11 \cdot 4$ & $11 \cdot 2$ & $10 \cdot 6$ & 9.6 & 0.42 & $\underset{* *}{* *}$ & & \\
\hline MUFA & $50 \cdot 1$ & 48.3 & $53 \cdot 3$ & $55 \cdot 6$ & $1 \cdot 12$ & $* * *$ & & $\ddagger$ \\
\hline 18: 1(n-9) & $43 \cdot 0$ & 41.5 & 44.9 & $46 \cdot 4$ & 0.85 & $* * *$ & & $\ddagger$ \\
\hline PUFA & $13 \cdot 4$ & $14 \cdot 6$ & $8 \cdot 2$ & $9 \cdot 4$ & 1.09 & $* * *$ & & \\
\hline $\mathrm{n}-6$ & $12 \cdot 0$ & $13 \cdot 5$ & 7.5 & $8 \cdot 1$ & 0.94 & $* * *$ & & \\
\hline 18: 2(n-6) & 9.8 & 10.9 & $6 \cdot 4$ & 6.9 & 0.72 & $* * *$ & & \\
\hline $\mathrm{n}-3$ & $1 \cdot 29$ & 1.06 & 0.59 & $1 \cdot 00$ & 0.254 & & & \\
\hline 18: 3(n-3) & $0 \cdot 86$ & $0 \cdot 62$ & $0 \cdot 46$ & $0 \cdot 80$ & 0.206 & & & \\
\hline \multicolumn{9}{|l|}{ Masseter } \\
\hline SFA & $34 \cdot 6$ & $35 \cdot 2$ & $34 \cdot 3$ & $33 \cdot 4$ & 0.84 & & & \\
\hline 16: 0 & $22 \cdot 3$ & $23 \cdot 0$ & $23 \cdot 4$ & $22 \cdot 9$ & 0.56 & & & \\
\hline 18: 0 & $10 \cdot 8$ & $10 \cdot 7$ & $9 \cdot 3$ & $9 \cdot 0$ & 0.34 & $* * *$ & & \\
\hline MUFA & $50 \cdot 1$ & $48 \cdot 1$ & 53.5 & $54 \cdot 3$ & 1.00 & $* * *$ & & \\
\hline 18: 1(n-9) & $42 \cdot 7$ & $40 \cdot 3$ & $43 \cdot 5$ & $44 \cdot 2$ & $0 \cdot 81$ & $* *$ & & $\ddagger$ \\
\hline PUFA & $15 \cdot 3$ & $16 \cdot 8$ & $12 \cdot 2$ & $12 \cdot 3$ & 0.95 & $* * *$ & & \\
\hline $\mathrm{n}-6$ & 14.5 & $16 \cdot 0$ & 11.6 & $11 \cdot 6$ & 0.94 & $* * *$ & & \\
\hline 18: 2(n-6) & $11 \cdot 1$ & $12 \cdot 5$ & 9.3 & 9.3 & 0.72 & ** & & \\
\hline $\mathrm{n}-3$ & 0.69 & 0.69 & 0.52 & 0.51 & 0.038 & $* * *$ & & \\
\hline $18: 3(n-3)$ & 0.38 & 0.39 & 0.32 & $0 \cdot 30$ & $0 \cdot 013$ & $* * *$ & & \\
\hline
\end{tabular}

+ SFA = total saturated fatty acids; MUFA = total monounsaturated fatty acids; PUFA = total polyunsaturated fatty acids; $\mathrm{n}-3=$ total $\mathrm{n}-3$ polyunsaturated fatty acids; $\mathrm{n}-6=$ total $\mathrm{n}-6$ polyunsaturated fatty acids.

$\ddagger$ Approached significance $(P<0 \cdot 10)$. 
breed 5 diet interaction effect in all three muscles analysed, and Iberian pigs given diet $\mathrm{A}$ had the highest MUFA proportions $(P<0 \cdot 10)$. PUFA proportion was the lowest (7 to $17 \%$ ) and differed between breeds. Landrace pigs showed a higher proportion $(P<0.001)$ of PUFA than Iberian pigs in all three muscle locations. In particular, the intramuscular fat of longissimus dorsi and gluteus medius of Iberian pigs showed a lower proportion of PUFA than other fat locations, like masseter or subcutaneous backfat. However, Landrace pigs showed a similar PUFA proportion, about 11 to $17 \%$, in all fat locations. The FA profile of intramuscular fat hardly differed between experimental diets.

\section{Discussion}

Comparisons between Iberian and Landrace pigs

Voluntary food and energy intake was significantly higher (by proportionately about 0.5 ) in Iberian than in Landrace pigs, which provides Iberian pigs with an extra source for lipogenesis. Moreover, Iberian pigs showed greater lipogenic enzyme activities (both in ME and in G6PDH) and energy depots in the backfat (71.7 v. $31.9 \mathrm{~mm}$ backfat thickness; $P<0.001)$ and intramuscular lipid content (in all three muscles locations; $P<0.001$ ) than Landrace pigs. Similar results have been reported by Serra et al. (1998), who compared these two breeds and also noted higher lipid contents in the subcutaneous and in intramuscular tissues of Iberian than in those of Landrace pigs. At earlier ages, Freire et al. (1998) also showed higher lipogenic enzyme activities in Iberian than in Large White post-weaning pigs, while at higher weights comparisons between other fat and lean breeds (Large White and Meishan pigs, respectively) have also evidenced these differences (Mourot et al., 1996).

To evaluate the genetic or dietary carbohydrate influence on the FA composition of adipose and muscular tissues, we provided diets with a similar content and FA composition. However, slight differences between experimental diets were observed in MUFA (Table 2), which was higher in $\operatorname{diet} \mathrm{M}$ than in diet $\mathrm{A}$. The present results reveal the effect of both the breed and diet on the composition of saturated, monounsaturated and polyunsaturated FA. It is known that the FA composition of adipose tissue is conditioned by its origin. Generally, PUFA are directly deposited from diet, because animals cannot synthesize them, while SFA are mostly obtained from synthesis de novo from dietary carbohydrate, and MUFA can be obtained from these two ways. From this perspective, there are more SFA and less PUFA in the fat depots of pigs with a genetic predisposition for obesity (Scott et al., 1981) or given food ad libitum (Wood, 1984) than in those of pigs selected for reduced backfat thickness or given food at a restricted level. Serra et al. (1998) observed a higher proportion of SFA and MUFA in the adipose tissues of Iberian pigs than in those of Landrace pigs, and attributed these differences to the higher lipogenesis of Iberian adipose tissues. In the present experiment, the backfat from Iberian pigs showed a lower proportion of PUFA and higher levels of MUFA, especially of oleic acid, but not of SFA. Iberian pigs may have genetic predisposition to store or synthesize MUFA de novo.

Intramuscular fat depots follow the same pattern as backfat but differences were not as marked. Iberian pigs showed higher MUFA and lower PUFA proportions than Landrace pigs, without differences in SFA. The differences observed in the present study between Iberian and Landrace intramuscular fat may be due to the particular adiposity of each breed. The higher fat content in muscles from Iberian pigs was promoted by a higher number and size of adipocytes, as reported by Etherton et al. (1982), who compared adipocyte cellularity between lean and obese breeds (Yorkshire and Ossabaw, respectively). Therefore, fewer FA are associated with membrane phospholipids and most of them are esterified to glycerol in adipocytes.

Differences between breeds in the adiposity of the intramuscular fat may explain why longissimus dorsi and gluteus medius intramuscular fat contents from Iberian pigs showed a lower PUFA proportion than backfat tissue, while Landrace showed similar PUFA contents in both tissues. Our results are in accordance with Ruiz et al. (1998) and Fontanillas et al. (1997), who analysed fat depots of Iberian and Landrace 5 Duroc, respectively. It seems that the intramuscular FA content of Iberian pigs was synthesized de novo to a higher extent and was less sensitive to dietary FA deposition.

Comparisons between maize- and acorn-sorghum-maizebased diets

The differences in composition between diets were mainly explained by a higher amount of starch and a lower amount of NSP in diet M. Starch is the storage polysaccharide of higher plants and a major source for animals. It is mostly digested in the small intestine of monogastric animals and absorbed as glucose, while NSP are mostly fermented in the large intestine. Volatile fatty acids, in particular acetate, are the main metabolites of carbohydrate fermentation and an additional source of energy for the animals, and can supply up to $0 \cdot 10$ to $0 \cdot 25$ of digestible energy in pigs (Bergman, 1990; Yen et al., 1991). However, the efficiency of fermentation is only 0.75 of the energy contained in carbohydrates, because of the 
energy used by microflora growth (Bergman, 1990). Therefore, and as a result of a higher intake, animals given diet $\mathrm{M}$ obtained a higher amount of energy than animals given diet A. Therefore, the daily liveweight gain $(P<0.05)$ and backfat depot $(P=0.07)$ were higher for animals given diet $\mathrm{M}$ than for those given diet $\mathrm{A}$.

Differences between diets were associated with higher $(P=0 \cdot 06)$ lipogenic enzyme activity in the subcutaneous adipose tissue of animals given diet $\mathrm{M}$. Higher lipogenic enzyme activities may be due to higher enzyme transcription, which requires glucose available to be induced (Towle et al., 1997). Glinsmann et al. (1986) reported higher fat synthesis in rats given free sugars than in those given starch. On the other hand, diets with a higher amount of fibre may affect lipogenesis (Hudgins et al., 1998), probably as a consequence of lower available energy or through the inhibitory effect of specific compounds such as propionate (Nishina and Freedland, 1990). However, there were no differences between experimental diets in the intramuscular fat content or lipogenic enzyme activities, which implies that despite having less energy available, animals given diet $\mathrm{A}$ showed the same intramuscular fat content as those given diet M. As discussed previously, intramuscular fat was not significantly affected by the quantity or substrate of available energy, and may rather depend on genetic factors.

The backfat profile is more affected by dietary fat than the intramuscular fat (Leszczynski et al., 1992; Fontanillas et al., 1997). In the present experiment, diet $\mathrm{M}$ contained higher MUFA and lower PUFA proportions than diet A. Experimental diets promoted differences in the FA backfat profile, depending on breed. Differences in the backfat profile were promoted by Iberian pigs given diet A, which showed the lowest SFA and highest MUFA proportions, in spite of the FA composition of diet A.

In conclusion, body fat and its distribution is strongly determined by genetic and to a lower extent by the diet. The high food intake of Iberian pigs provides high energy for de novo lipogenesis, while the dietary composition and in particular the amount of glucose absorbed may allow higher subcutaneous fat synthesis. Moreover, Iberian pigs have a higher ability to synthesize or store MUFA, which may be due to a higher $\Delta 9$-desaturase activity. Intramuscular fat content is particularly influenced by genetic factors and not by the diet. Fermentable carbohydrates, which give less energy absorbed, mostly as acetate, can thus promote a similar intramuscular fat content by reducing the backfat depot. These results should reinforce research on the influence of fermentable carbohydrates on body fat distribution.

\section{Acknowledgements}

This study was supported by the CICYT funded project AGF98-0506.

\section{References}

Allee, G. L., Romsos, D. R., Leveille, G. A. and Baker, D. H. 1971. Influence of age on in vitro lipid biosynthesis and enzymatic activity in pig adipose tissue. Proceedings of the Society for Experimental Biology and Medicine 137: 449-452.

Association of Official Analytical Chemists. 1995. Official methods of analysis. Association of Official Analytical Chemists, Arlington, VA.

Bergman, E. N. 1990. Energy contributions of volatile fatty acids from the gastrointestinal tract in various species. Physiological Reviewss 70: 567-590.

Champ, M. 1992. Determination of resistant starch in foods and food products: interlaboratory study. European Journal of Clinical Nutrition 46: (suppl. 1) s51-s61.

Etherton, T. D., Wangsness, P. J., Hammers, V. M. and Ziegler, J. H. 1982. Effect of dietary restriction on carcass composition and adipocyte cellularity of swine with different propensities for obesity. Journal of Nutrition 112: 2314-2323.

Fitch, W. M., Hill, R. and Chaikoff, I. L. 1959. The effect of fructose feeding on glycolitic enzyme activities of the normal rat liver. Journal of Biological Chemistry 234: 1048-1051.

Folch, J., Lees, M. and Slaon-Stanley, G. N. 1957. A simple method for the isolation and purification of total lipids from animal tissues. Journal of Biological Chemistry 226: 497-509.

Fontanillas, R., Barroeta, A., Baucells, M. D. and Codony, R. 1997. Effect of feeding highly cis-monounsaturated, trans, or n-3 fats on lipid composition of muscle and adipose tissue of pigs. Journal of Agricultural and Food Chemistry 45: 3070-3075.

Freire, J. P., Mourot, J., Cunha, L. F., Almeida, J. A. and Aumaitre, A. 1998. Effect of the source of dietary fat on post-weaning lipogenesis in lean and fat genotypes of pigs. Annals of Nutrition and Metabolism 42: 90-95.

Gandemer, G., Pascal, G. and Durand, G. 1983. Lipogenic capacity and relative contribution of the different tissues and organs to lipid synthesis in male rat. Reproduction, Nutrition, Development 23: 575-588.

Glinsmann, W. H., Irausquin, H. and Park, Y. K. 1986. Evaluation of health aspects of sugars contained in carbohydrate sweeteners. Journal of Nutrition 116: (suppl.) S1-216.

Guardiola, F., Codony, R., Rafecas, M., Boatella, J. and Lopez, A. 1994. Fatty acid composition and nutritional value of fresh eggs from large- and small-scale farms. Journal of Food Composition and Analysis 7: 171-188.

Hsu, R. Y. and Lardy, H. A. 1969. Malic enzyme. In Methods in enzymology no. 17 (ed. J. M. Lowenstein), pp. 230-235. Academic Press, New York. 
Hudgins, L. C., Hellerstein, M. K., Seidman, C. E., Neese, R. A., Tremaroli, J. D. and Hirsch, J. 2000. Relationship between carbohydrate-induced hypertriglyceridemia and fatty acid synthesis in lean and obese subjects. Journal of Lipid Research 41: 595-604.

Hudgins, L. C., Seidman, C. E., Diakun, J. and Hirsch, J. 1998. Human fatty acid synthesis is reduced after the substitution of dietary starch for sugar. American Journal of Clinical Nutrition 67: 631-639.

Karlsson, A., Enfält, A. -C., Essén-Gustavsson, B., Lundström, K., Rydhmer, L. and Stern, S. 1993. Muscle histochemical and biochemical properties in relation to meat quality during selection for increased lean tissue growth rate in pigs. Journal of Animal Science 71: 930-938.

Leszczynski, D. E., Pikul, J., Easter, R. A., McKeith, F. K. McLaren, D. G., Novakofski, J., Bechtel, P. J. and Jewell, D. E. 1992. Characterization of lipid in loin and bacon from finishing pigs fed full-fat soybeans or tallow. Journal of Animal Science 70: 2175-2181.

Lopez-Bote, C. J. 1998. Sustained utilization of the Iberian pig breed. Meat Science 49: S17-S27.

Mersmann, H. J. 1986. Lipid metabolism in swine. In Swine in cardiovascular research, volume 1 (ed. H. C. Stanton and H. J. Mersmann), pp. 75-103. CRC Press, Florida.

Mittendorfer, B., Sidossis, L. S., Walser, E., Chinkes, D. L. and Wolfe, R. R. 1998. Regional acetate kinetics and oxidation in human volunteers. American Journal of Physiology 274: E978-E983.

Morales, J., Pérez, J. F., Baucells, M. D., Mourot, J. and Gasa, J. 2002a. Comparative digestibility and lipogenic activity in Landrace and Iberian finishing pigs fed ad libitum corn- and corn-sorghum-acorn based diets. Livestock Production Science 77: 195-205.

Morales, J., Pérez, J. F., Martín-Orúe, S. M., Fondevila, M. and Gasa, J. 2002b. Large bowel fermentation of corn or sorghum-acorn diets fed as a different source of carbohydrates to Landrace and Iberian pigs. British Journal of Nutrition 88: 489-497.

Mourot, J. and Hermier, D. 2001. Lipids in monogastric animal meat. Reproduction, Nutrition, Development 41: 109-118.

Mourot, J., Kouba, M. and Bonneau, M. 1996. Comparative study of in vitro lipogenesis in various adipose tissues in the growing Meishan pig: comparison with the Large White pig (Sus domesticus). Comparative Biochemistry and Physiology 115b: 383-388.
National Research Council. 1998. Nutrient requirements of swine, 10th edition. National Academy Press, Washington, DC.

Nishina, P. M. and Freedland, R. A. 1990. Effects of propionate on lipid biosynthesis in isolated rat hepatocytes. Journal of Nutrition 120: 668-673.

Ovilo, C., Pérez-Enciso, M., Barragán, C., Clop, A., Rodríguez, C., Oliver, M. A., Toro, M. A. and Noguera, J. L. 2000. A QTL for intramuscular fat and backfat thickness is located on porcine chromosome 6. Mammalian Genome 11: 344-346.

Pond, W. G., Jung, H. G. and Varel, V. H. 1988. Effect of dietary fiber on young adult genetically lean, obese and contemporary pigs: body weight, carcass measurements, organ weights and digesta content. Journal of Animal Science 66: 699-706.

Ramsey, C. B., Tribble, L. F., Wu, C. and Lind, K. D. 1990. Effects of grains, marbling and sex on pork tenderness and composition. Journal of Animal Science 68: 148-154.

Ruiz, J., Cava, R., Antequera, T., Martín, L., Ventanas, J. and López-Bote, C. J. 1998. Prediction of the feeding background of Iberian pigs using the fatty acid profile of subcutaneous, muscle and hepatic fat. Meat Science 49: 155-163.

Scott, R. A., Cornelius, S. G. and Mersmann, H. J. 1981. Fatty acid composition of adipose tissue from lean and obese swine. Journal of Animal Science 53: 977-981.

Serra, X., Gil, F., Pérez-Enciso, M., Oliver, M. A., Vázquez, J. M., Gispert, M., Díaz, I., Moreno, F., Latorre, R. and Noguera, J. L. 1998. A comparison of carcass, meat quality and histochemical characteristics of Iberian (Guadyerbas line) and Landrace pigs. Livestock Production Science 56: 215-223.

Theander, O. 1991. Chemical analysis of lignocellulosic material. Animal Feed Science and Technology 32: 35-44.

Towle, H. C., Kaytor, E. N. and Shih, H. M. 1997. Regulation of the expression of lipogenic enzyme genes by carbohydrate. Annual Review of Nutrition 17: 405-433.

Wood, J. D. 1984. Fat quality in pigmeat - UK. In Fat quality in lean pigs. Meat Research Institute, special report no. 2, pp. 9-14. Commission of European Community, Brussels.

Yen, J. T., Nienaber, J. A., Hill, D. A. and Pond, W. G. 1991. Potential contribution of absorbed volatile fatty acids to whole-animal energy requirement in conscious swine. Journal of Animal Science 69: 2001-2012.

(Received 2 December 2002-Accepted 5 May 2003) 